\title{
Meticulous lymph node dissection and gross pathological examination improves survival in non-small cell lung cancer patients
}

\author{
Matthias Heldwein ${ }^{1}$, Maximilian Michel $^{2}$, Fabian Doerr ${ }^{1}$, Khosro Hekmat ${ }^{1}$ \\ ${ }^{1}$ Department of Cardiothoracic Surgery, ${ }^{2}$ Department of Zoology, University of Cologne, Cologne, Germany \\ Correspondence to: Prof. Dr. Khosro Hekmat. Director of Thoracic Surgery Program, Department of Cardiothoracic Surgery, University of Cologne, \\ Kerpener Strasse 62, 50937 Cologne, Germany. Email: khosro.hekmat@uk-koeln.de. \\ Provenance: This is an invited Editorial commissioned by Executive Editor-in-Chief Jianxing He (Director of the Thoracic Surgery Department, The \\ First Affiliated Hospital of Guangzhou Medical University, Guangzhou, China). \\ Comment on: Ray MA, Faris NR, Smeltzer MP, et al. Effectiveness of Implemented Interventions on Pathologic Nodal Staging of Non-Small Cell \\ Lung Cancer. Ann Thorac Surg 2018;106:228-34.
}

Submitted Aug 20, 2018. Accepted for publication Sep 12, 2018.

doi: $10.21037 /$ jtd.2018.09.53

View this article at: http://dx.doi.org/10.21037/jtd.2018.09.53

Meticulous intraoperative lymph-node staging is one of the most important factors in determining an adequate prognosis and therapy for non-small cell lung cancer (NSCLC) patients (1). Especially for surgeons with little experience in the field of oncological thoracic surgery, a systematic, and thus careful lymphadenectomy (LAD) required for an operable NSCLC patient, is not an everyday challenge and can potentially lead to a diminished outcome for the patient who has to undergo this surgery.

The research by Ray et al. (2) covers a multi-center dataset of 2,469 patients that underwent a lobar resection in early stages of NSCLC. The authors implemented a novel dissection kit for surgeons, which helped to specify the systematic approach of LAD anatomically, targeted lymph node sampling and was designed according to the ACOSOG Z0030 trial (3). Collection of the individual lymph node stations as well as communication process in regards to the examination process with pathologists were recorded and documented in a previously validated manner using prescribed vessels and algorithms $(4,5)$. Furthermore, the specimens obtained from the anatomical resections were prepared far into the periphery of the bronchial tree, and the lymph nodes were examined histologically according to a new gross lung dissection protocol (6). These measures were implemented in order to improve the quality of the surgical lymph node dissection, as well as the subsequent pathological examination. The study showed that a combination of both of the interventions brought the best results in staging NSCLC patients. However, the long-term survival rate could not be presented yet, as the implemented interventions were introduced only recently (2).

Historically, systematic LAD has already been described by Naruke et al. in 1976. After introducing a first map of the mediastinal lymph nodes, research started to compare the sampling of a tumor-suspected lymph node or nodes with a systematic LAD to evaluate the benefit for early stage NSCLC patients (7). In 1997 Mountain and Dresler revised the Naruke map and were the first to classify the lymph nodes around the main-stem bronchus as N2 (8). The consequence was an upstaging of several stage II Narukepatients to IIIA according to the new MD-ATS map, which had changed the prognosis and therapy for the patients. In 2009 this was followed by the International Association for the Study of Lung Cancer (IASLC) lymph node map, the first to define the entire subcarinal group as level 7 (9).

Changes in the classification system were necessary, because the superiority of the systematic lymph node dissection over lymph node sampling as measured on the basis of long-term survival, has been both demonstrated and refuted (10-13). An evidence level 1b meta-analysis of these studies has showed that there was no significant heterogeneity between the studies, and therefore a pooled analysis was performed. This revealed that the overall survival after a systematic LAD was significantly higher 
than after lymph node sampling (14). Regardless of the T-stage and tumor localization, dissection should always be complete and non-selective. Systematic ipsilateral lymph node dissection is now recommended as standard procedure since:

(I) The common complications after systematic LAD are well controlled;

(II) Systematic LAD leads to more accurate staging;

(III) Systematic LAD in early stage NSCLC patients improves prognosis.

The other aspect addressed by the dissection kit used in the present study (2), is concerning the examination of the lymph nodes. This has been fraught with difficulties in literature, since studies vary in what terminology is used, contents of lymph node dissection and the assignment of lymph node compartments. Research for the accuracy of lymph node tagging was performed in a prospective, non-randomized evidence level $2 \mathrm{~b}$ trial and a prospective, randomized evidence level $1 \mathrm{~b}$ assessment $(15,16)$. In both studies, a multilevel N2 situation was detected significantly more often than after a systematic LAD when compared with lymph node sampling, suggesting that systematic LAD leads to a clearer histological profiling and subsequent prediction of relapse.

From an international perspective, these developments in NSCLC surgery and pathology have led to the inclusion of systematic LAD in the national guidelines for the treatment of NSCLC. Ever more certifying and controlling institutions such as the German Cancer Society (DKG) and OnkoZert, call for a systematic LAD as a quality criterion in the national certification processes of lung cancer centers (17). OnkoZert is an independent certification institute which organizes, on behalf of the German Cancer Society, annual audits for organ cancer centers. However, it should be mentioned that DKG and OnkoZert further demand a minimum amount of annual expertise in addition to the high quality standards. It is therefore not only required to know how to perform a systematic LAD, but also to provide evidence of practical experience in the form of an annually reported number of early stage NSCLC patients treated by anatomical (e.g., segmentectomy, lobectomy) resection at the department. In Germany, a department of thoracic surgery which performs less than 75 anatomical resections in NSCLC patients or less than 100 systematic lymphadenectomies in anatomical lung resections per year does not qualify in the national certification process, this is on the basis of insufficient practical clinical experience and manual knowledge $(18,19)$.
The present study by Ray et al. (2) provides not only support for the introduction of such proof of the surgical skill, practice and quality, but goes one step further and provides a practical solution for places where such criteria cannot be met. The authors carried out a multi-center study of four contiguous regions in a tri-state area including Arkansas, Mississippi and Tennessee. Eleven medical centers were included, each with an annual minimum of 5 curativeintent lung cancer resections. The dataset of 2,469 patients collected over the period of eight years, accounts for an average annual performance of 28 anatomical resections per participating center (2). Unfortunately, we do not have a detailed breakdown of the operations carried out at the individual departments, but a wide spread between hospitals is to be expected. The minimum inclusion criterion of 5 annual operations suggests that there are participating low volume medical centers (likely rural areas) as well as higher volume medical centers (likely from urban catchment areas). And here is the crux of this contribution; our colleagues who are mostly from Memphis, Tennessee have managed to provide guidance on high quality LAD with their specimen collection kit. A guide that does justice to the importance of adequate and thorough lymph node staging and which can be brought on site to the mentioned low volume centers. In our opinion, this is a great way to significantly improve the quality of oncological lung surgeries, even in rural areas with smaller hospitals whose low annual intervention number would be expected to render high quality lung cancer treatment difficult or even impossible.

In conclusion, specialized thoracic surgeons are associated with a better postoperative morbidity and mortality. To improve the overall quality of care, NSCLC patients should be treated primarily in certified, high volume lung centers. The suggested lymph node collection kit may be beneficial for low volume centers.

\section{Acknowledgements}

None.

\section{Footnote}

Conflict of Interest: The authors have no conflicts of interest to declare

\section{References}

1. Jin $\mathrm{Y}$, Chen $\mathrm{M}, \mathrm{Yu} \mathrm{X}$. Comparison of the $7(\mathrm{th})$ and 
proposed 8(th) editions of the AJCC/UICC TNM staging system for non-small cell lung cancer undergoing radical surgery. Sci Rep 2016;6:33587.

2. Ray MA, Faris NR, Smeltzer MP, et al. Effectiveness of Implemented Interventions on Pathologic Nodal Staging of Non-Small Cell Lung Cancer. Ann Thorac Surg 2018;106:228-34.

3. Darling GE, Allen MS, Decker PA, et al. Randomized trial of mediastinal lymph node sampling versus complete lymphadenectomy during pulmonary resection in the patient with N0 or N1 (less than hilar) non-small cell carcinoma: results of the American College of Surgery Oncology Group Z0030 Trial. J Thorac Cardiovasc Surg 2011;141:662-70.

4. Osarogiagbon RU, Miller LE, Ramirez RA, et al. Use of a surgical specimen-collection kit to improve mediastinal lymph-node examination of resectable lung cancer. J Thorac Oncol 2012;7:1276-82.

5. Fibla JJ, Cassivi SD, Decker PA, et al. Validation of the lung cancer staging system revisions using a large prospective clinical trial database (ACOSOG Z0030). Eur J Cardiothorac Surg 2013;43:911-4.

6. Liang W, He J, Shen Y, et al. Impact of Examined Lymph Node Count on Precise Staging and Long-Term Survival of Resected Non-Small-Cell Lung Cancer: A Population Study of the US SEER Database and a Chinese MultiInstitutional Registry. J Clin Oncol 2017;35:1162-70.

7. Naruke T, Suemasu K, Ishikawa S. Surgical treatment for lung cancer with metastasis to mediastinal lymph nodes. J Thorac Cardiovasc Surg 1976;71:279-85.

8. Mountain CF, Dresler CM. Regional lymph node classification for lung cancer staging. Chest 1997;111:1718-23.

9. Rusch VW, Asamura H, Watanabe H. The IASLC lung cancer staging project: a proposal for a new international lymph node map in the forthcoming seventh edition of the TNM classification for lung cancer. J Thorac Oncol 2009;4:568-77.

10. Wu Y, Huang ZF, Wang SY, et al. A randomized trial of systematic nodal dissection in resectable non-small cell lung cancer. Lung Cancer 2002;36:1-6.

11. Sugi K, Nawata K, Fujita N, et al. Systematic lymph node dissection for clinically diagnosed peripheral non-smallcell lung cancer less than $2 \mathrm{~cm}$ in diameter. World J Surg
1998;22:290-4.

12. Izbicki JR, Thetter O, Habekost M, et al. Radical systematic mediastinal lymphadenectomy in non-small cell lung cancer: a randomized controlled trial. Br J Surg 1994;81:229-35.

13. Izbicki JR, Passlick B, Pantel K, et al. Effectiveness of radical systematic mediastinal lymphadenectomy in patients with resectable non-small cell lung cancer: results of a prospective randomized trial. Ann Surg 1998;227:138-44.

14. Wright G, Manser RL, Byrnes G, et al. Surgery for nonsmall cell lung cancer: systematic review and meta-analysis of randomized controlled trials. Thorax 2006;61:597-603.

15. Keller S. M, Adak S, Wagner H, et al. A randomized trial of postoperative adjuvant therapy in patients with completely resected stage II or IIIA non-small-cell lung cancer. Eastern Cooperative Oncology Group. N Engl J Med 2000;343:1217-22.

16. Izbicki JR, Passlick B, Karg O, et al. Impact of radical systematic mediastinal lymphadenectomy on tumor staging in lung cancer. Ann Thorac Surg 1995;59:209-14.

17. Goeckenjan G, Sitter H, Thomas M, et al. Prävention, Diagnostik, Therapie und Nachsorge des Lungenkarzinoms. Pneumologie 2010;64:e1-e164.

18. Catalogue of Requirements Lung Cancer Centres of the German Cancer Society (Deutsche Krebsgesellschaft DKG) page 28/39;5.2.2. Available online: http://ecc-cert. eu/fileadmin/user_upload/Catalogue_of_Requirements_ Lung_2018.docx

19. Catalogue of Requirements Lung Cancer Centres of the German Cancer Society (Deutsche Krebsgesellschaft DKG) page 29/39;5.2.4. Available online: http://ecc-cert. eu/fileadmin/user_upload/Catalogue_of_Requirements_ Lung_2018.docx

(English Language Editor: Jeremy Dean Chapnick, AME Publishing Company)

Cite this article as: Heldwein M, Michel M, Doerr F, Hekmat K. Meticulous lymph node dissection and gross pathological examination improves survival in non-small cell lung cancer patients. J Thorac Dis 2018;10(Suppl 33):S3951-S3953. doi: 10.21037/jtd.2018.09.53 